Farklı yüzey hazırlık işlemlerinin rezin bazlı, polimer infiltre seramik ve feldspatik cad/cam materyallerinin yüzey pürüzlülüğüne etkisi

\section{The effect of surface preparation methods on the surface roughness of resin based, polymer infiltrated ceramic and feldspatic CAD/CAM materials}

\author{
Dr. Öğr. Üyesi Burcu Dikici \\ Yeditepe Üniversitesi, Diş Hekimliği Fakültesi \\ Restoratif Diş Tedavisi A.D., İstanbul \\ Orcid ID: 0000-0003-3944-4840
}

Öğr. Gör. Dr. Elif Türkeş Başaran

Yeditepe Üniversitesi, Diş Hekimliği Fakültesi

Restoratif Diş Tedavisi A.D., İstanbul

Orcid ID: 0000-0001-6199-0472

Prof. Dr. Esra Can

Yeditepe Üniversitesi, Diş Hekimliği Fakültesi

Restoratif Diş Tedavisi A.D., İstanbul

Orcid ID: 0000-0003-3585-4949

Geliş tarihi: 22 Kasım 2019

Kabul tarihi: 26 Kasım 2019

doi: 10.5505/yeditepe.2020.44712

\author{
Yazışma adresi: \\ Dr. Öğr. Üyesi Burcu Dikici \\ Yeditepe Üniversitesi, Diş Hekimliği Fakültesi, \\ Restoratif Diş Tedavisi A.D. \\ Bağdat Cad. No:238 34728 istanbul \\ Tel: :+90 2163636044 \\ E-posta: burcutoydemir@gmail.com
}

ÖZET

Amaç: Bu çalışmanın amacı farklı yüzey hazırlama işlemlerinin rezin bazlı, polimer infiltre seramik ve feldspatik bazlı CAD/ CAM materyallerinin yüzey pürüzlülüğüne etkisini incelemektir.

Gereç ve Yöntem: Rezin bazlı (Lava; 3M ESPE ve Cerasmart; GC), polimer infiltre seramik (Enamic; Vita) ve feldspatik seramik (Cerec; Sirona Dentsply) CAD/CAM bloklar $2 \mathrm{~mm}$ kalınlıkta örneklere ayrıldı ve her bir CAD/CAM materyalinden 30'ar adet örnek elde edildi. Rezin bazlı CAD/CAM blokları kendi içinde cila, kontrol (kumlama (SB)), kombine uygulama (kumlama+hidroflorik asit (SB+HF)); seramik bazlı CAD/CAM blokları ise cila, kontrol (hidroflorik asit (HF)), kombine uygulama $(\mathrm{SB}+\mathrm{HF})$ olmak üzere $3^{\prime}$ er alt gruba ayrıldı $(\mathrm{n}=10)$. Cila grubunda örnekler 1200 gritlik SiC zımparaya kadar cilalandı. Kumlama grubunda örnekler $50 \mu \mathrm{m}$ alüminyum oksit ile kumlanırken, HF asit grubunda örnekler \%5'lik HF asit (Ultradent) ile 60 sn asitlendi. Kombine gruplarda örnekler kumlama işlemini takiben asitlendi. Tüm örneklerin yüzey pürüzlülük değerleri (Ra) profilometre cihazı (Perthometer M1 Mahr) kullanılarak ölçüldü. Sonuçlar one way ANOVA ve post hoc Tukey testleri ile değerlendirildi $(p<0.05)$.

Bulgular: Cilalanmış Cerec en düşük yüzey pürüzlülük değerlerini verirken, Enamic istatistiksel olarak en yüksek Ra değeri göstermiştir $(p<0,01)$. Yüzey işlemleri bütün materyallerde yüzey pürüzlülükleri istatistiksel olarak anlamlı düzeyde artmıştır $(p<0,01)$. HF asit uygulaması sonrası Enamic, Cerec grubuna kıyasla istatistiksel olarak daha yüksek Ra değeri gösterirken $(p<0,01)$, kumlama sonrası Cerasmart ve Lava grupları arasında fark gözlenmemiştir ( $p=0,446)$. Kombine uygulamalar sonucunda en yüksek yüzey pürüzlülüğü Cerasmart'ta izlenmiştir.

Sonuçlar: Cerec materyalinin en az pürüzlülük değerine sahip CAD/CAM blok olduğu gözlenmiştir. Yüzey işlemleri rezin, polimer infiltre ve feldspatik bazlı CAD/CAM materyallerinin yüzey pürüzlülüklerini arttırmış ve bu etki materyalin yapısına göre değişiklik göstermiştir.

Anahtar kelimeler: CAD/CAM, kumlama, asitleme, yüzey pürüzlülüğü

\section{SUMMARY}

Aim: The aim of this study was to determine the effect of surface preparation methods on the surface roughness of resin based, polymer infiltrated ceramic and feldspatic CAD/CAM materials.

Materials and Method: Two types of resin based CAD/CAM materials (Lava; 3MESPE and Cerasmart; GC), polymer infiltrated ceramic (Enamic; Vita), and feldspatic ceramic (Cerec; Sirona, Dentsply) blocks were cut into slabs of $2 \mathrm{~mm}$ thickness and 30 specimens were obtained from each CAD/CAM blocks. While resin based blocks were divided into three subgroups as untreated, control (sandblasting (SB)), combined (sandblasting+ hydrofluoric acid $(\mathrm{SB}+\mathrm{HF})$ ); ceramic groups were divided into three subgroups as untreated, control (HF 
etch), combined $((\mathrm{SB}+\mathrm{HF}))$. In untreated groups, specimens were polished up to 1200 grit SiC paper while sandblasted with $50 \mu \mathrm{m}$ aluminum oxide in SB groups. In $\mathrm{SB}+\mathrm{HF}$ groups, the specimens were sandblasted and etched. Surface roughness $(\mathrm{Ra})$ were measured using digital profilometer (Marh, Perthometer M2). Statistical analysis was performed using One-way ANOVA and post hoc Tukey test.

Results: The lowest Ra value was obtained with untreated Cerec blocks while Enamic resulted in significantly highest Ra value $(p<0,01)$. Surface preparation methods significantly increased the surface roughness of CAD/CAM materials $(p<0,01)$. Following HF etch, Enamic exhibited significantly higher Ra values than Cerec. After sandblasting, Cerasmart and Lava showed significantly similar Ra values. Following combined preparation methods, Cerasmart showed the highest Ra values.

Conclusions: Cerec CAD/CAM blocks exhibited the smoothest surface. Sandblasting and acid etching resulted in increased surface roughness of resin based, polymer infiltrated and feldspatic CAD/CAM materials and its effects differs from the material structure.

Keywords: CAD/CAM blocks, sandblasting, etching, roughness

\section{Giriș}

Dijital diş hekimliğinin gelişmesine paralel olarak, seramik bazlı materyaller ile birlikte polimer infiltre seramik materyalleri ve yüksek sıcaklık ve basınç altında üretilen rezin bazlı CAD/CAM materyalleri piyasaya sürülmüştür. ${ }^{1,2}$ Polimer infiltre seramik ve rezin bazlı CAD/CAM materyalleri, iyi marjinal adaptasyonları, elastisite modullerinin dentine yakın olması ve kolay tamir edilebilmeleri nedeniyle klinikte seramik bazlı CAD/CAM materyallerine göre avantaj sağlamaktadır. ${ }^{3,4,5}$ Ayrıca, antagonist dentisyonu daha az aşındırmaları ve restorasyonda daha az kııı̆a neden olmaları gibi özellikleri ile de klinikte seramik bazlı CAD/ CAM materyallerine göre üstünlükleri bulunmaktadır. ${ }^{6,7}$ İndirekt adeziv restorasyonların klinik başarısı, restorasyon materyali ve adeziv simantasyonda kullanılan rezin siman ile rezin siman ve diş sert dokuları arasındaki mikromekanik ve kimyasal adezyona bağlıdır. ${ }^{8,9,10}$ Bu nedenle, ideal ve stabil bir adezyonun sağlanmasında, uygun rezin siman ve CAD/CAM materyalinin seçimi kadar, CAD/CAM materyalinin yapısına uygun olarak gerçekleştirilen yüzey hazırlık işlemleri de önem taşımaktadır. ${ }^{6,11} \mathrm{CAD} / \mathrm{CAM}$ bloklarının bağlanma yüzeyine yapılan uygulamaların diş sert dokularına olan bağlanma dayanımını da etkilediği bildirilmiştir. ${ }^{9,10}$ Yüzey işlemleri adeziv simantasyonda kullanılan rezin siman ile CAD/CAM materyalinin bağlanmasını arttırırken aynı zamanda klinikte tamir gerektiren durumlarda tamir materyali ile restorasyonun bağlanmasını da arttırmaktadır. ${ }^{8-10}$

Genel olarak, seramik ve kompozit bazlı CAD/CAM mater- yallerinin yüzeylerine uygulanan hazırlık işlemlerinin ama$\mathrm{cl}$, mikroporozite oluşturarak temas alanının arttırmak, yüzey enerjisi ve ıslanabilirliği arttırmak ve rezin simanın infiltrasyonunu kolaylaştırarak mikromekanik adezyonu sağlamaktadır. ${ }^{12} \mathrm{Bu}$ amaçla, polimer bazlı CAD/CAM materyallerinin adeziv simantasyonu öncesinde önerilen işlemler, yüzeyin kumlanması veya silika kaplanmasıdır. Kumlama işlemi, yüzeyin temizlenmesi ve yüzey pürüzlülüğü yaratarak mikromekanik retansiyonun arttırılması için önemlidir. ${ }^{13,14}$ Kumlamanın etkinliğini ise; partikül büyüklüğü, uygulama basıncı ve süresi, kumlama cihazının açısı gibi değişkenler etkilemektedir. ${ }^{15} \mathrm{Bu}$ amaçla 50 mikronluk Al2O3 kullanılabileceği gibi 30 mikronluk $\mathrm{SiO} 2$ partikülleri de kullanılabilmektedir. Al2O3 partikülleri ile yapılan kumlama işleminde, zayıf porselen parçacıkların uzaklaştırılması ile pürüzlü bir yüzey elde edilmekte ve mikromekanik bağlanma sağlanmaktadır. Bu işlem, 2 bar basınç altında 5-20 saniye süre ile, yüzeyde mat bir görüntü elde edilene kadar uygulanır. ${ }^{16}$ Kumlama sonrası, kumlanan yüzeyin temizlenmesi de bağlanma dayanımı açısından çok önemlidir ve bu sebeple yüzeyin alkol ile temizlenmesi önerilmektedir. ${ }^{17}$

Seramik bazlı CAD/CAM restorasyonların simantasyonunda ise, bağlanma yüzeylerinin simantasyon öncesi hidroflorik asitle (HF) asitlenmesi önerilmektedir. ${ }^{18}$ Hidroflorik asit, silikon dioksit ile reaksiyona girerek seramiğin cam fazını çözmesi sonucu yüzey pürüzlülüğünü ve bağlanmayı arttırmaktadır. ${ }^{19,20,21}$ Cam seramiklerin rezin simanlara bağlanmasındaki ilk aşama restorasyonun iç yüzeyindeki porozitenin arttırımasıdır. Kumlama ve silika kaplama işlemleri, mekanik olarak porselenin iç yüzeyini hazırlar ancak, porselenin direncinde azalma meydana getirir. $\mathrm{Bu}$ amaçla, literatürde bu tip materyaller için en çok önerilen protokol HF asit uygulamasıdır. ${ }^{19,20} \mathrm{HF}$ asit genellikle \% 2-5 konsantrasyonlarda yaklaşık $60 \mathrm{sn}$. süre ile uygulanmaktadır. ${ }^{11} \mathrm{HF}$ asit, tercihli olarak cam seramiklerin cam matriksini çözer. ${ }^{22}$ Feldspatik, lösit ile güçlendirilmiş ve lityum disilikat ile güçlendirilmiş seramiklerin yapısı farklı olduğundan HF asidin uygulama süresi değişiklik göstermektedir. Feldspatik seramikler, lösit ve lityum disilikat ile güçlendirilmiş olan seramiklerden daha uzun süre asitlenmelidir.

Asitleme sonrası, yüzey pürüzlülüğü ile birlikte yüzeyin ıslanabiliriliği de artmakta ve seramik yüzeylerinde bulunan hidroksil grupları daha sonra yüzeye uygulanan silan ile bağlanmaktadır. ${ }^{23}$ Silan, asitleme sonrası CAD/CAM materyalinin yüzeyinde açığa çıkan inorganik partiküller ile yapıştııcı olarak kullanılan rezin simanın organik kısmının kimyasal olarak birbirine bağlanmasını sağlamaktadır. ${ }^{23}$ Taramalı elektron mikroskobu (SEM), hazırlanan yüzeylerin detaylarının incelenmesinde sıklıkla kullanılan bir yöntemdir. SEM örneklerinin görüntüsünün büyütülmesinde elektron ışığı kullanmaktadır. SEM'de, elektron lensleri ta- 
rafından odaklanan elektron ışını hazırlanan örneğin üzerini tarar ve sinyaller görüntü olarak algılanır. Bu yöntemin avantajları, alan derinliğinin fazla olması, yüksek çözünürlüklü görüntü elde edilmesi ve görüntülerin yüzeylerinin net ve detaylı bir şekilde gözlenmesidir. ${ }^{24}$ Ayrıca pürüzlü yüzeye sahip örneklerin yüksek büyütmelerde incelenmesinde kolaylık sağlaması bu tekniğin en önemli avantajlarından biridir. ${ }^{24}$

Bu çalışmada bir feldspatik, bir polimer infiltre seramik, bir nano seramik ve bir kompozit bazlı CAD/CAM materyalinin farklı yüzey işlemleri sonrasında yüzey pürüzlülüğünün değerlendirilmesi ve yüzey morfolojilerinin SEM ile incelenmesi amaçlanmıştır.

\section{GEREÇ VE YÖNTEM}

Bu çalışmada, rezin bazlı (Lava Ultimate Restorative; 3M ESPE ve Cerasmart; GC), polimer infiltre seramik bazlı (Enamic; Vita) ve feldspatik bazlı (Cerec; Sirona Dentsply) CAD/CAM blok kullanıldı (Tablo 1).

Tablo 1. Çalışmada kullanılan materyaller, içerikleri ve üretici firmaları

\begin{tabular}{|c|c|c|c|}
\hline Materyal & Materyal Tip & Üretici Firma & İçerik \\
\hline Cerasmart & $\begin{array}{l}\text { Kompozit } \\
\text { CAD/CAM blok }\end{array}$ & $\begin{array}{l}\text { GC Corp,Tokyo, } \\
\text { Japan }\end{array}$ & $\begin{array}{l}\text { Bis-MEPP, UDMA, DMA } \\
\text { Nanopartikül rezin içeren silika ve baryum cam } \\
(71 \%) \text {. }\end{array}$ \\
\hline $\begin{array}{l}\text { Lava } \\
\text { Ultimate }\end{array}$ & $\begin{array}{l}\text { Rezin } \\
\text { Nanoseramik } \\
\text { CAD/CAM blok }\end{array}$ & $\begin{array}{l}\text { 3MESPE, St. } \\
\text { Paul, MN, USA }\end{array}$ & $\begin{array}{l}\text { Bis-GMA, UDMA, Bis-EMA, TEGDMA silika } \\
\text { nanomerleri }(20 \mathrm{~nm}) \text {, zirkon nanomerleri }(4-11 \mathrm{~nm}) \\
\text { zirkonya ve silika nanoclusterlar1 }(80 \%)\end{array}$ \\
\hline Vita Enamik & $\begin{array}{l}\text { Polimer infiltre } \\
\text { seramik } \\
\text { CAD/CAM blok }\end{array}$ & $\begin{array}{l}\text { Vita Zahnfabrik, } \\
\text { Germany }\end{array}$ & $\begin{array}{l}\text { Polimer kismI (25\%) UDMA ve TEGDMA } \\
\text { Seramik Kism: silicon dioksit 58-63\%, } \\
\text { aluminyum oksit } 20-23 \% \text {, sodyum oksit } 9-11 \% \text {, } \\
\text { potasyum oksit } 4-6 \% \text {, boron trioksit } 0.5-2 \%, \\
\text { zirconya ve kalsiyum oksit } \\
\text { (86 wt. } \%)\end{array}$ \\
\hline Cerec & $\begin{array}{l}\text { Feldspatik } \\
\text { CAD/CAM blok }\end{array}$ & $\begin{array}{l}\text { Sirona Dentsply, } \\
\text { USA }\end{array}$ & $\begin{array}{l}\text { Cam matriks içine gömülü feldspatik partiküller } \\
\left(\mathrm{SiO}_{2} \mathrm{Al}_{2} \mathrm{O}_{3} \mathrm{Na}_{2} \mathrm{O} \quad \mathrm{K}_{2} \mathrm{O} \mathrm{CaO} \mathrm{TiO}\right.\end{array}$ \\
\hline
\end{tabular}

CAD/CAM bloklar düşük devirli elmas bıçak (Isomet, Buehler LTD) kullanılarak 2 mm kalınlıkta örneklere ayrıldı ve her bir CAD/CAM materyalinden 30'ar adet örnek elde edildi ( $n=30$ ). Örneklerin yüzeyleri sırasıyla 600,800 ve 1200 gritlik silikon karbid zımparalarla su soğutması altında cilalandı (Buehler, Lake Bluff, IL USA). Rezin bazlı CAD/ CAM blokları kendi içinde cila, kontrol (kumlama (SB)), kombine uygulama (kumlama+hidroflorik asit $(\mathrm{SB}+\mathrm{HF})$ ); seramik ve polimer infiltre seramik bazlı CAD/CAM blokları ise cila, kontrol (hidroflorik asit (HF)), kombine uygulama (kumlama+hidroflorik asit $(\mathrm{SB}+\mathrm{HF})$ ) olmak üzere 3 'er alt gruba ayrıldı $(n=10)$. Cila gruplarında yüzeylere cilalama sonrası herhangi bir işlem uygulanmadı. Kontrol grupları içinde kumlama işleminde yüzeyler $50 \mu \mathrm{m}$ alüminyum oksit ile 15 saniye 2 bar basınç altında kumlanırken, HF asit uygulamasında yüzeylere \% $5^{\prime}$ lik HF asit (Ultradent) 60 saniye uygulandı, yıkandı ve kurutuldu. Kombine uygulama gruplarıda (SB+HF) ise yüzeyler kumlama işlemi sonrasında \%5'lik HF asit ile asitlendi. Kumlama ve HF asit uygulamalarını takiben bütün örneklerin yüzeyleri ultrasonik temizleme cihazı (Piezon ${ }^{\circledR}$ OEM built-in kit EMS, Switzerland) ile temizlendi.
Tüm örneklerin yüzey pürüzlülük değerleri (Ra) profilometre cihazı (Perthometer M1 Mahr, Göttingen, Almanya) kullanılarak ölçüldü. Örneklerin yüzey pürüzlülük ölçümleri, $4 \mathrm{~mm}$ aralıklarda ve cihazın ucu $2 \mathrm{~mm} / \mathrm{sn}$ hızla ilerletilerek 3 farklı yerden yapıldı ve aritmetik ortalaması alınarak ortalama yüzey pürüzlülüğü $(R a, u ̨ m)$ tespit edildi. Profilometre cihazı her grubun ölçümü öncesinde kalibre edildi. Daha sonra her bir gruptan örnek seçilerek yüzeyleri etanol ile temizlenip altın ile kaplandı ve taramalı elektron mikroskobu ile yüzey morfolojileri 500 ve 1000 büyütmelerle incelendi (6335-F, JEOL Ltd). Sonuçlar one way ANOVA ve post hoc Tukey testleri ile değerlendirildi $(\mathrm{p}<0,05)$.

\section{BULGULAR}

Çalışmada farklı yüzey hazırlama işlemleri yapılmış CAD/ CAM bloklarına ait elde edilen yüzey pürüzlülük ortalama ve standart sapma değerleri Tablo 2'de gösterilmiştir.

Tablo 2. Çalışmada farklı yüzey hazırlama işlemleri yapılmış CAD/CAM bloklarına ait elde edilen yüzey pürüzlülük ortalama ve standart sapma değerleri (Ra)

\begin{tabular}{|l|l|l|l|}
\hline & Kombine \\
& Cila & Kontrol & $\begin{array}{l}\text { Kumlama+HF Asit } \\
\text { (SB+HF) }\end{array}$ \\
\hline Cerec & $0,27 \pm 0,003^{\mathrm{a}, \mathrm{A}}$ & $0,406 \pm 0,05^{\mathrm{b}, \mathrm{D}}$ & $0,95 \pm 0,089^{\mathrm{c}, \mathrm{G}}$ \\
\hline Cerasmart & $0,05 \pm 0,008^{\mathrm{d}, \mathrm{B}}$ & $1,19 \pm 0,07^{\mathrm{e}, \mathrm{E}}$ & $1,39 \pm 0,048^{\mathrm{f}, \mathrm{H}}$ \\
\hline Lava & $0,069 \pm 0,008^{\mathrm{g}, \mathrm{C}}$ & $1,15 \pm 0,044^{\mathrm{h}, \mathrm{E}}$ & $1,28 \pm, 075^{\mathrm{i}, \mathrm{J}}$ \\
\hline Enamic & $0,067 \pm 0,008^{\mathrm{j}, \mathrm{C}}$ & $0,62 \pm 0,034^{\mathrm{k}, \mathrm{F}}$ & $1,26 \pm 0,084^{1, \mathrm{~J}}$ \\
\hline
\end{tabular}

Kücük harfler aynı materyal icerisinde farklı yüzey ișlemlerindeki farklılıkları gös terirken, büyük harfler aynı yüzey işlemlerinin farklı materyallerde meydana getirdiği istatistiksel farklııkları göstermektedir.

Cilalanmış olan bütün CAD/CAM bloklar yapısal özelliklerine bağlı olarak farklı yüzey pürüzlülükleri göstermiştir. Cilalanmış Cerec en düşük yüzey pürüzlülük değerlerini verirken, Enamic istatistiksel olarak en yüksek Ra değeri göstermiştir $(p<0,01)$. Cilalanmış rezin bazlı CAD/CAM bloklar kendi aralarında karşılaşıııldığında Lava, Cerasmart'tan istatistiksel olarak daha pürüzlü yüzey morfolojisi sergilemiștir $(p<0,01)$. Cilalanmıș Lava ve Enamic grupları arasında fark gözlenmezken ( $p=0,994)$, bu gruplar istatistiksel olarak cilalanmış Cerec ve Cerasmart'tan daha yüksek pürüzlülük değerleri göstermiştir $(p<0,01)$.

Cilalanmış CAD/CAM blokların SEM görüntüleri incelendiğinde, Cerasmart'ta küçük, düzensiz yapıda inorganik doldurucular izlenirken, Lava'nın yapısında büyük, küresel doldurucular saptanmıştır. Cilalanmış Cerec yüzeyi Enamic'e göre daha pürüzsüz bir görüntü sergilemiştir (Resim 1,2,3,4). 


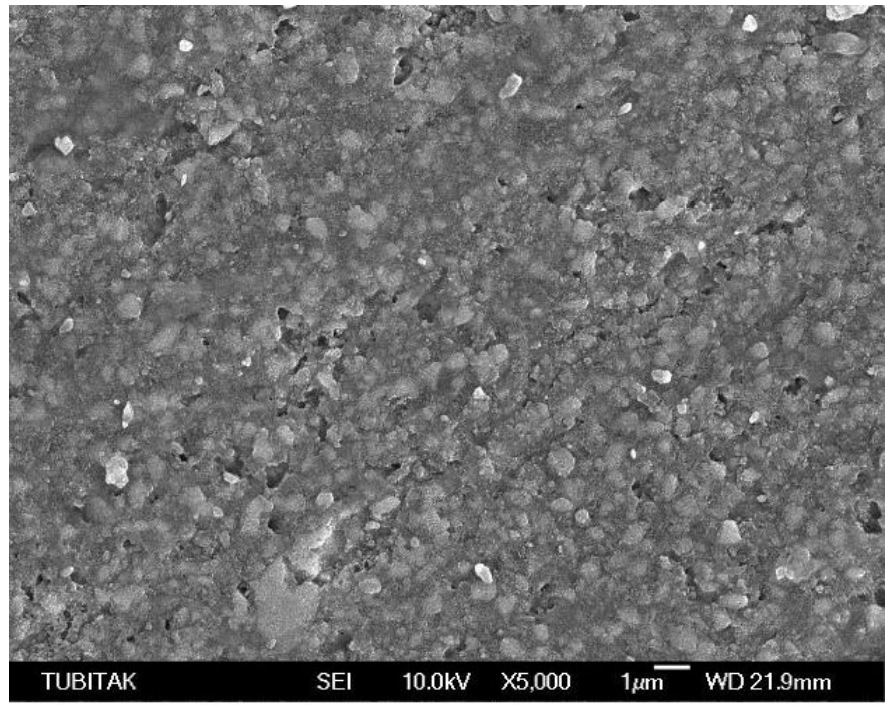

Resim 1. Cilalanmış Cerasmart CAD/CAM materyalinin SEM görüntüsü

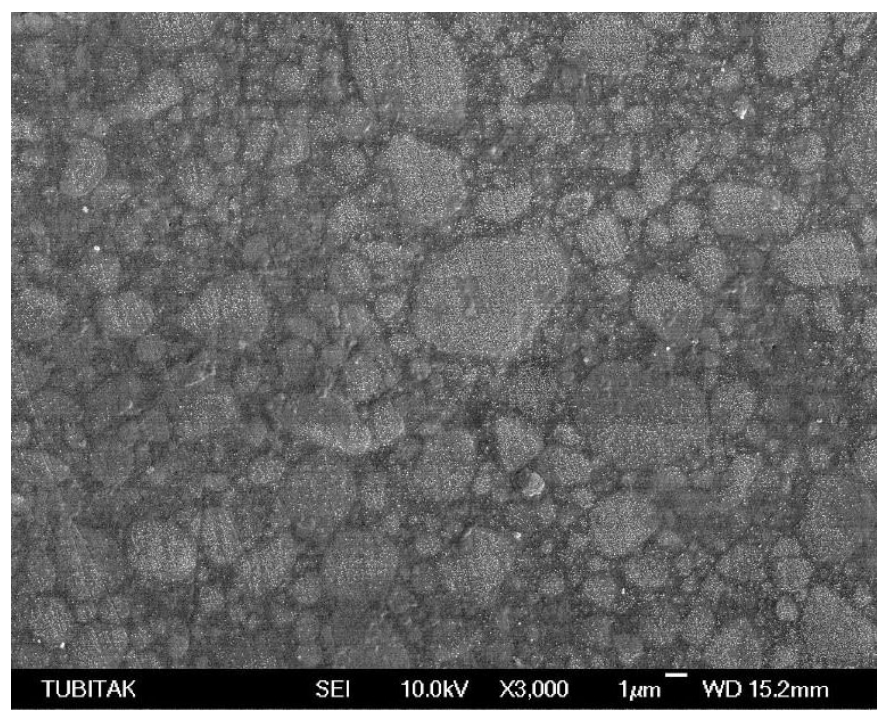

Resim 2. Cilalanmış Lava CAD/CAM materyalinin SEM görüntüsü

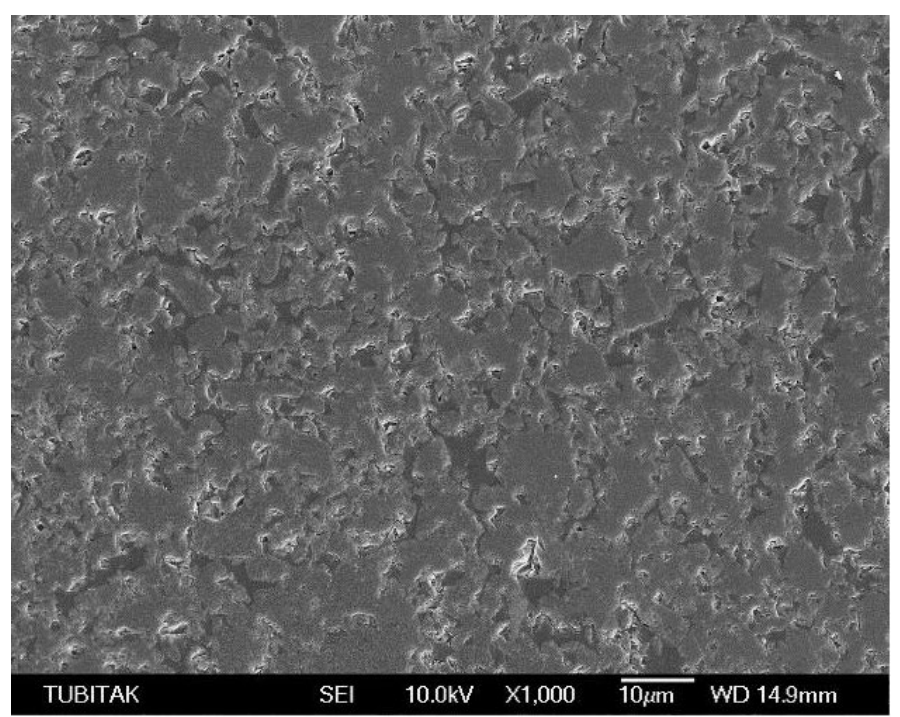

Resim 3. Cilalanmış Enamic CAD/CAM materyalinin SEM görüntüsü

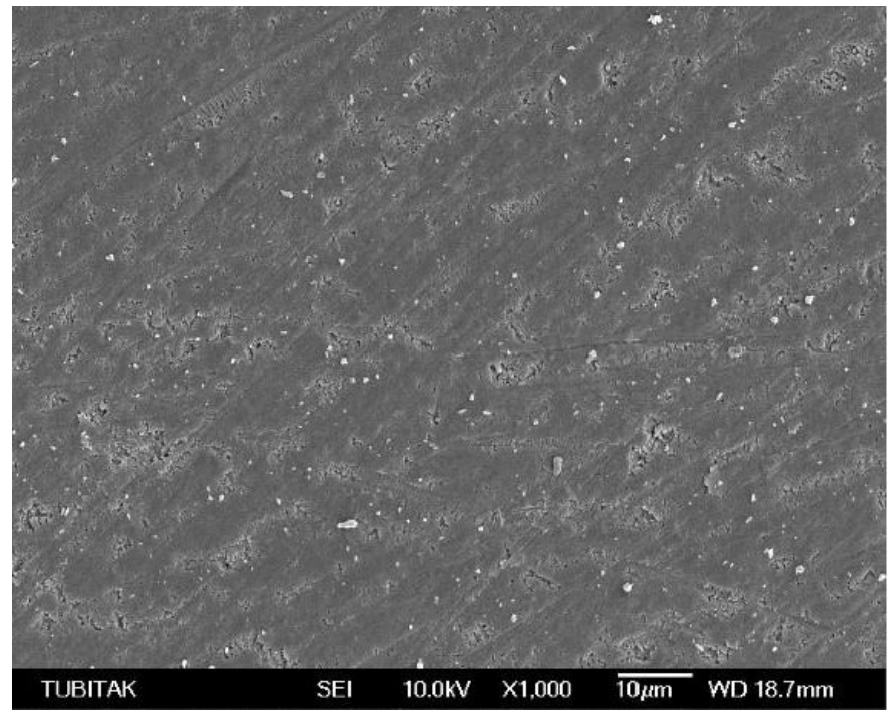

Resim 4. Cilalanmış Cerec CAD/CAM materyalinin SEM görüntüsü

CAD/CAM bloklarına uygulanan yüzey işlemleri sonrası bütün materyallerde yüzey pürüzlülükleri cila gruplarına göre istatistiksel olarak anlamlı düzeyde artmıştır $(p<0,01)$. HF asit uygulaması sonrası Enamic, Cerec grubuna kıyasla istatistiksel olarak daha yüksek Ra değeri gösterirken $(p<0,01)$, kumlama sonrası Cerasmart ve Lava grupları arasında fark gözlenmemiştir $(p=0,446)$. Kumlama işlemi yapılan rezin bazlı CAD/CAM materyalleri, HF asit uygulanan seramik esaslı materyallerden anlamlı derecede yüksek Ra değerleri vermiştir $(p<0,01)$.

HF asit uygulanmış Enamic ve Cerec'in SEM görüntüleri incelendiğinde, uygulanan asitin seramik yüzeyinde çözünme meydana getirdiği ve polimer ağı ortaya çıkardığı gözlemlenmiştir (Resim 7,8). Oluşan bu çözünmeyle birlikte materyallerin yüzeylerinde gözenekli yapılar izlenmiştir. Kumlama yapılan rezin bazlı Lava ve Cerasmart blokların SEM görüntülerinde ise, her iki materyalin de kumlama işlemi sonrasında retantif yüzeylerin oluştuğu saptanmıştır (Resim 5,6).

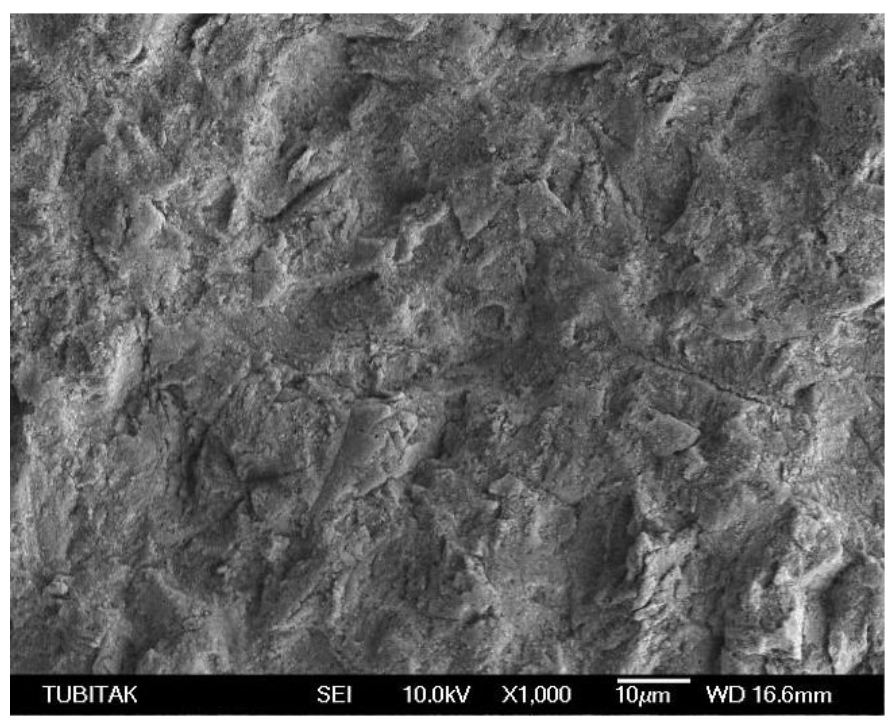

Resim 5. $50 \mu \mathrm{m}$ alüminyum oksit ile kumlanmış Cerasmart yüzeyinin SEM görüntüsü 


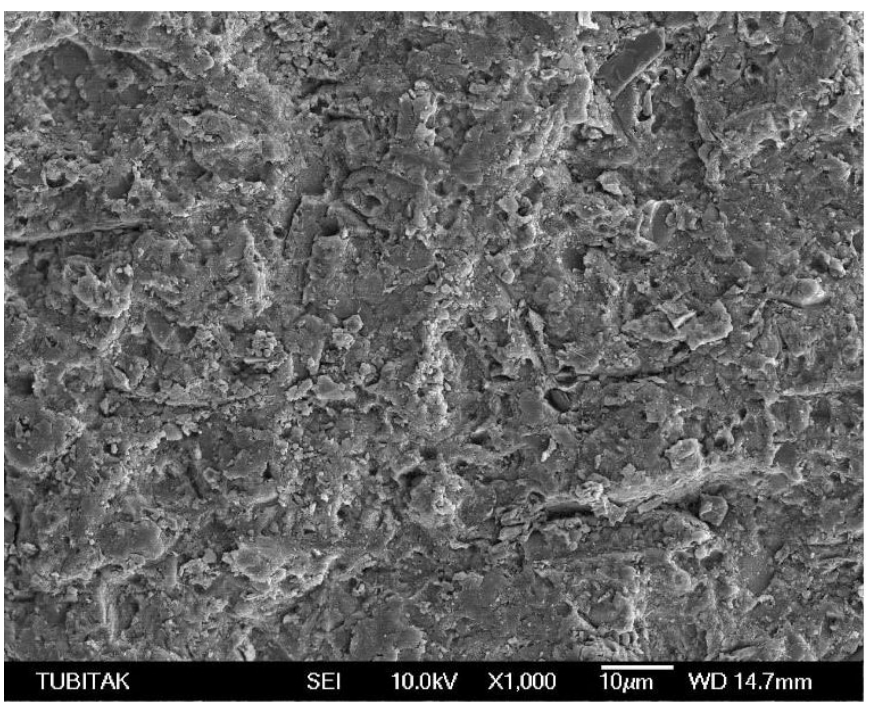

Resim 6. $50 \mu \mathrm{m}$ alüminyum oksit ile kumlanmış Lava yüzeyinin SEM görüntüsü

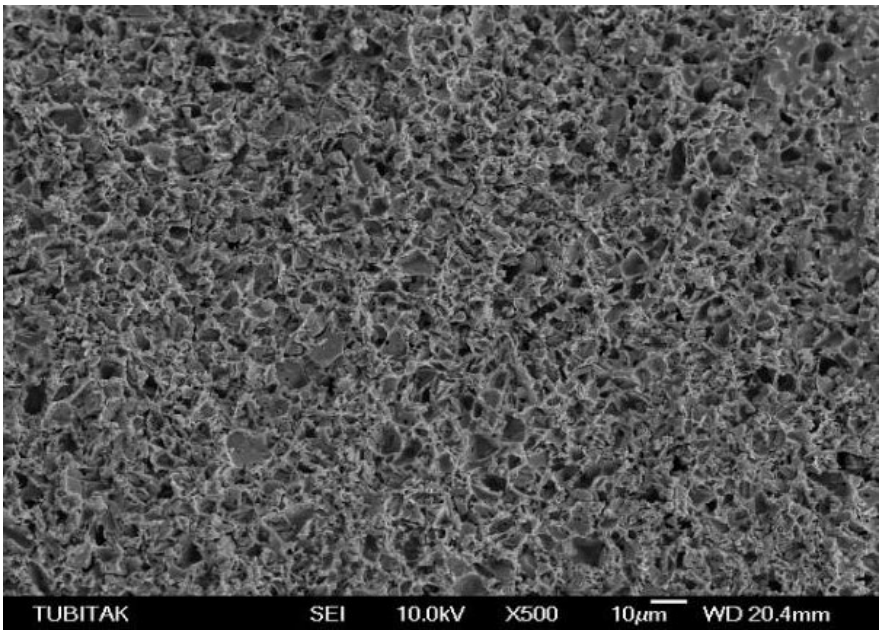

Resim 7. \%5'lik HF asit uygulanmış Enamic yüzeyinin SEM görüntüsü

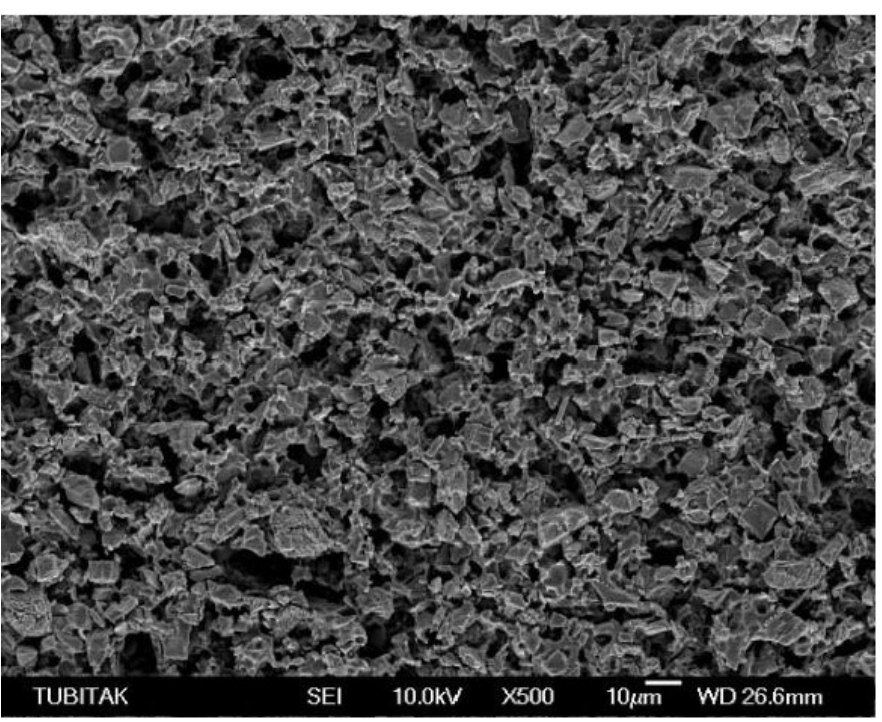

Resim 8. \%5lik HF asit uygulanmış Cerec yüzeyinin SEM görüntüsü

Kumlama ve HF asidin kombine uygulandığı gruplarda bütün CAD/CAM materyallerinin yüzey pürüzlülüğünün sadece kumlama ve sadece HF asit uygulanmış kontrol gruplarına göre istatistiksel olarak anlamlı düzeyde arttığı gözlenmiş̧ir $(p<0,01)$. Uygulamalar sonrası en düşük pürüzlülük değeri Cerec grubunda gözlenirken, en yüksek yüzey pürüzlülüğü Cerasmart’ta izlenmiştir. Kombine uy- gulama yapılan Lava ve Enamic grupları ise benzer yüzey pürüzlülük değerleri göstermiştir ( $p=0,793)$. Kumlama ve HF asit uygulamalarının her ikisinin de yapıldığı kombine grupların SEM görüntülerinde ise, Cerasmart ve Lava yüzeylerinde mikroporların oluştuğu görülmüştür (Resim $9,10)$.

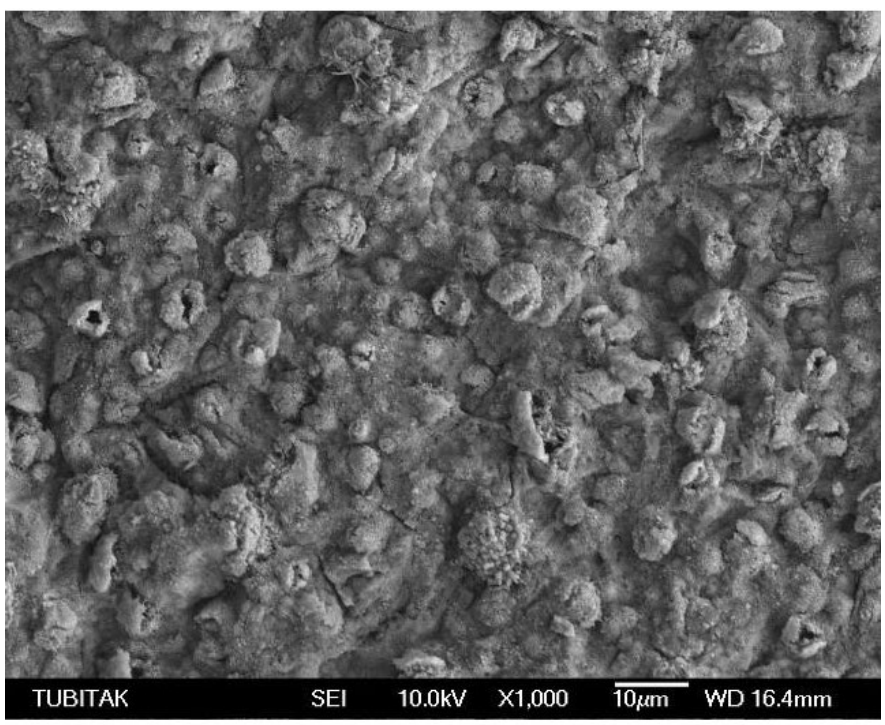

Resim 9. Kombine uygulama yapılmış (Kumlama+HF asit) Cerasmart yüzeyinin SEM görüntüsü

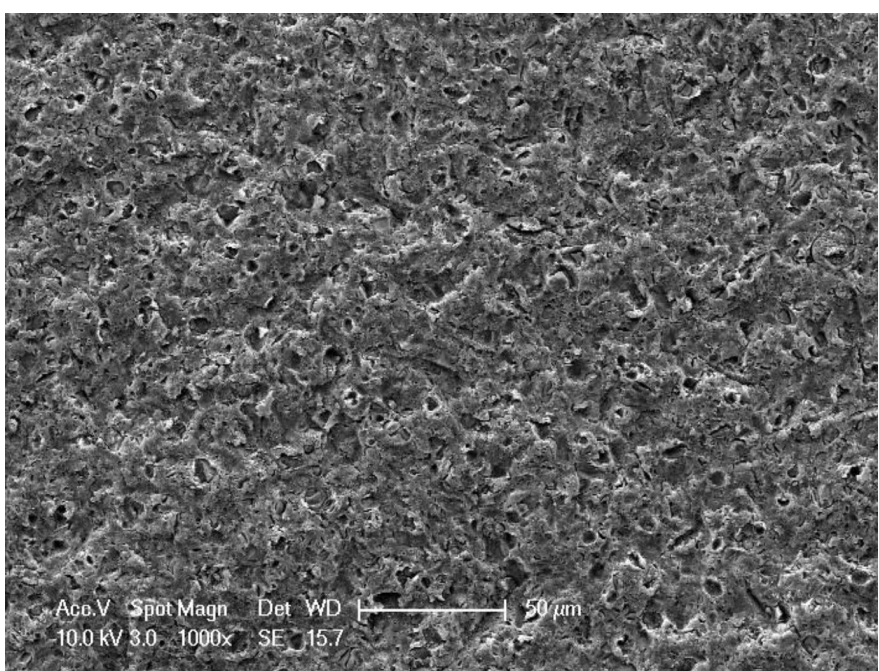

Resim 10. Kombine uygulama yapılmış (Kumlama+HF asit ) Lava yüzeyinin SEM görüntüsü

Enamic ve Cerec'te ise camsı yapıdaki matriksinin çözündüğü saptanmıştır (Resim 11,12). Buna ek olarak ise polimer infiltre ve feldspatik CAD/CAM bloklarda kumlama sonrasında yüzey morfolojilerinde mikroçatlaklar gözlenmiştir (Resim 11,12). 


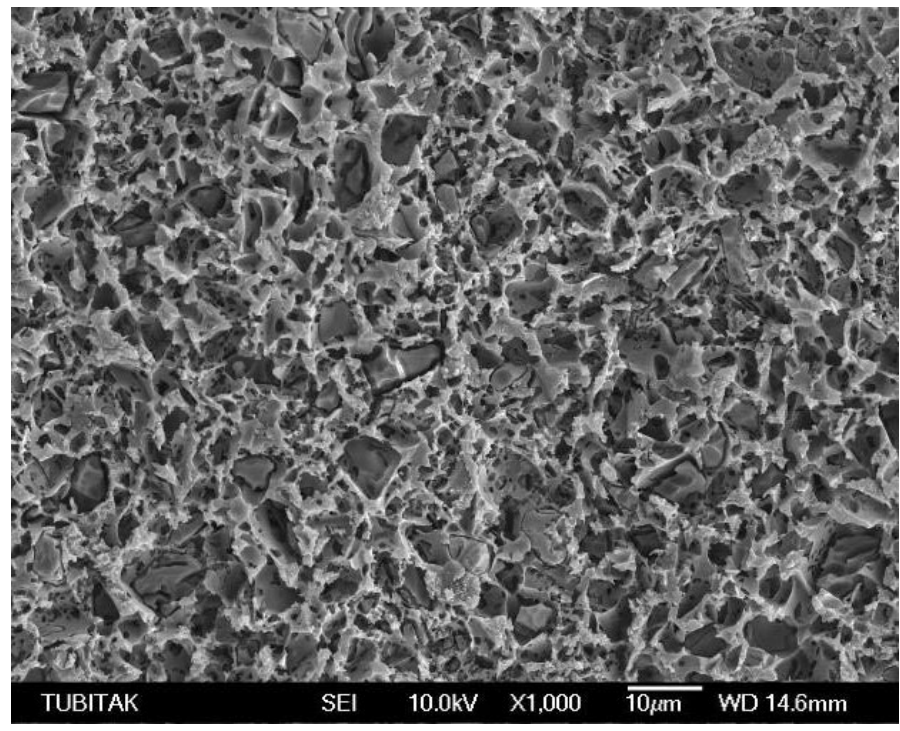

Resim 11. Kombine uygulama yapılmıș (Kumlama+HF asit) Enamic yüzeyinin SEM görüntüsü

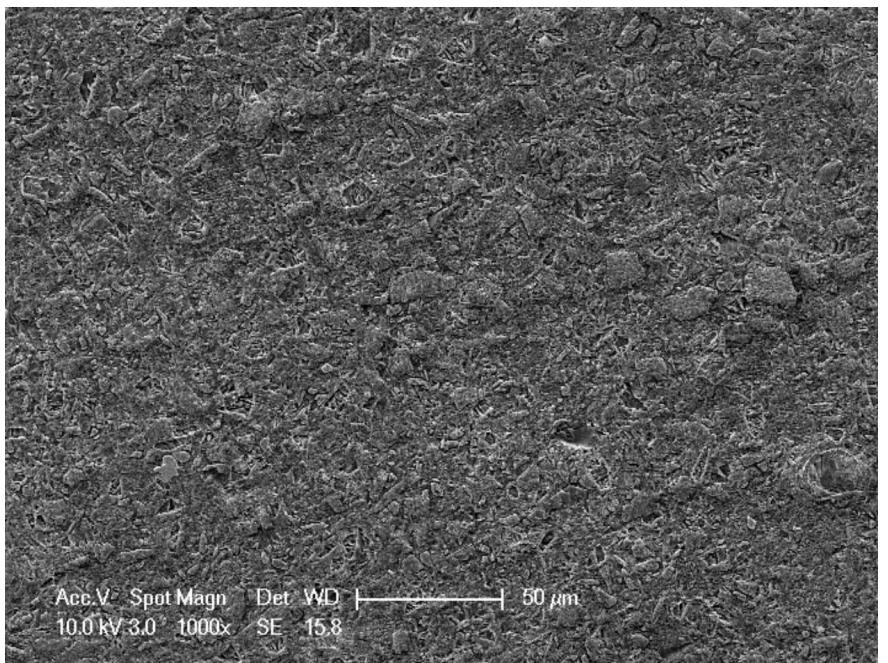

Resim 12. Kombine uygulama yapılmış (Kumlama+HF asit ) Cerec yüzeyinin SEM görüntüsü

\section{TARTIŞMA}

Son zamanlarda, indirekt restorasyonların klinik başarısında, diş sert dokuları ve restorasyonlar arasındaki bağlanmanın yanısıra rezin siman ve restoratif materyaller arasındaki mikro-mekanik ve kimyasal bağlanmanın etkisi de önem kazanmıştır., ${ }^{6,8}$ Restoratif materyal ve rezin siman arasındaki bağlanmanın kalitesi indirekt restorasyonların performansının belirlenmesinde önemli rol oynamaktadır. ${ }^{25}$ CAD/CAM bloklara uygulanan yüzey işlemleri, restoratif materyal ve rezin siman arasında mekanik bağlanmayı sağlayarak bağlanma dayanımını arttırmaktadır. ${ }^{26,27}$ Yüzey pürüzlülüğü, yüzey hazırlık işlemlerinin etkisinin en iyi şekilde ifade edilmesini sağlamaktadır. ${ }^{28,29}$ Kompozit bazlı indirekt restorasyonlarda mekanik olarak yüzeyin pürüzlendirilmesinin kimyasal yöntemlere göre bağlanma performansı açısından daha etkili olduğu düşünülmektedir. ${ }^{13}$ Bununla birlikte, pürüzlülügün fazla olması ve pürüzlendirme işlemi sırasında meydana gelen çatlaklar restorasyonun performansını azaltabilmektedir. ${ }^{30}$

Bu çalışmada bir feldspatik, bir polimer infiltre seramik, bir nano seramik ve bir kompozit bazlı CAD/CAM mater- yalinin farklı yüzey işlemleri sonrasında yüzey pürüzlülüğünün değerlendirilmesi ve yüzey morfolojilerinin SEM ile incelenmesi amaçlanmıştır.

Materyallerin yüzeyine uygulanan kumlama ve asitleme işlemleri yüzey hazırlığı için en çok tercih edilen yöntemlerdendir. ${ }^{31}$ Seramik bazlı veya polimer infiltre seramik restorasyonların yüzey hazırlığında, HF asit uygulaması tercih edilirken, kompozit bazlı CAD/CAM restorasyonlarda yüzeyin kumlanması tavsiye edilmektedir. ${ }^{17}$ Frankenberger ${ }^{32}$, Vita Enamic için HF asit ile asitlemeyi önerirken, Lava için kumlamanın daha etkili olacağını önermiştir. Feldspatik porselenler için ise, HF asit uygulaması en çok tercih edilen pürüzlendirme yöntemidir. ${ }^{23,33}$ Asitleme süresi, yüzey hasarının olmaması için önemlidir ve uzun süre asit uygulanması yüzeyde çatlaklara sebep olabilmektedir. ${ }^{29} \mathrm{Bu}$ çalışmada, üretici firmaların talimatlarına uygun şekilde kompozit bazlı materyallerde kumlama, seramik bazlı CAD/CAM matertallerinde HF asit uygulaması tercih edilmiştir.

Indirekt restoratif materyallerin bağlanma yüzeyinde gerçekleştirilen kumlama işlemi, ıslanabilirlik ve yüzey alanını arttırarak mekanik bağlanmayı güçlendirmekte ve bağlanma dayanımını arttırmaktadır. ${ }^{26,27}$ Ancak, kumlama işleminin yüzeyi kontamine ederek veya yüzeyde çok fazla pürüzlendirme yaparak bağlanmayı olumsuz etkileyebileceğini de gösteren çalışmalar bulunmaktadır. ${ }^{34,35}$ Kumlamanın yüksek basınçla yüzeyde çok fazla hasar meydana getirebileceği bildirilmiş ve düşük basınçla kumlamanın daha etkili olduğu gösterilmiştir. ${ }^{5}$ Bu nedenle, bu çalışmada üretici firmaların da talimatlarına uygun şekilde $50 \mu \mathrm{m}$ alüminyum oksit ile 15 saniye 2 bar basınç altında kumlama işlemi gerçekleştirilmiş, yüzeyler SEM ile incelenerek bulgular desteklenmiştir.

Enamic yüzeylerinin adeziv bağlanmasında HF asit, Cojet ve kumlama yöntemleri önerilmekle birlikte, en etkili bağlanmanın HF asit ile elde edileceği bildirilmiştir.28 Bununla birlikte, kumlama ile de yüksek bağlanma sonuçları elde edilebileceği savunulmuştur. ${ }^{6}$ Bu çalışmada, asit ve kumlamanın birlikte yapıldığı kombine pürüzlendirme işlemi de uygulanmıştır. Asitleme sonrası kumlama ile yüzey pürüzlülüğünde meydana gelen değişimlerin incelenmesi amaçlanmıştır.

Çalışmanın bulgularına göre, cilalanmış Cerec yüzeyi en düşük pürüzlülük değerlerine sahiptir $(p>0,05)$. Cilalanmış Lava ve Enamic yüzeylerinin pürüzlülük değerleri arasında istatistiksel olarak anlamlı bir fark gözlenmezken, bu iki materyalin pürüzlülük değerleri Cerasmart materyalinden istatistiksel olarak daha yüksek bulunmuştur $(p>0,05)$.

SEM görüntülerinde cilalanmış Enamic yüzeyinde mikroporozitelerin olduğu seramik ve polimer yapıların birbirine geçtiği ağsı bir yapı gözlenmektedir (Resim 3). Cilalanmış Cerasmart yüzeyinde maksimum $1 \mu \mathrm{m}$ boyutunda farklı yapıda doldurucular izlenirken, Lava yüzeyinde nano- 
metrik partiküllerin yanısıra büyük doldurucular da (5-10 $\mu \mathrm{m})$ gözlenmiştir (Resim 1,2). Cilalanmış Lava yüzeyi daha küçük porozitelerin olduğu homojen bir yüzeye sahiptir. Cilalanmış Cerec yüzeyi en pürüzsüz yüzey görüntüsü verirken, Cilalanmış Enamic yüzeyinin Cerasmart ve Lavaya göre daha pürüzlü olduğu gözlenmişir (Resim 1,2,3,4).

Cilalanmış yüzeylerdeki pürüzlülük farklııılarının materyallerin yapısal farklııklarından dolayı olduğu düşünülmektedir. Cerec \%63 feldspatik kristalin partiküllerinden oluşan doldurucu oranına sahipken, Cerasmart \%71 oranında silika ve baryum cam doldurucu içermektedir. Lava \%80 oranında nanoseramik rezin seramik doldurucu içerirken, Enamic ise \%85 oranında oksitle güçlendirilmiş felsdpatik doldurucu içermektedir. ${ }^{6,8}$ Doldurucu oranı az olan materyallerin daha düşük yüzey pürülülük değerleri gösterdiği bilinmektedir. Bu çalışmanın sonuçları da geçmiş çalışmalarla benzerlik göstermektedir.

Bu çalışmada kompozit bazlı CAD/CAM blokların yüzeylerine kontrol grubu olarak üretici firmaların ve literatürün önerdiği şekilde kumlama işlemi uygulanmış, polimer infiltre seramik ve feldspatik porselen içeren CAD/CAM materyallerine ise $\mathrm{HF}$ asit uygulanmıştır. Bütün CAD/CAM yüzeylerinin pürüzlülük değerleri cilalanmış yüzeylere göre istatistiksel olarak anlamlı şekilde artmıştır ( $p>0,05)$. Kumlama sonrası Lava ve Cerasmart istatistiksel olarak en pürüzlü yüzeylere sahiptir ve aralarında istatistiksel bir fark gözlenmemektedir. Ancak, SEM görüntülerinde Lava örneklerinin yüzeyleri, Cerasmart yüzeylerine göre daha pürüzlü olarak gözlenmiştir (Resim 5,6).

$\mathrm{HF}$ asit seramik bazlı indirekt restoratif materyallerin camsı veya kristalin yapısını çözerek yüzey morfolojisine etki etmektedir. ${ }^{5,36}$ Della Bona ve Noort, HF asidin feldspatik seramiklerdeki camsı yapı içerisinde bulunan silika ile etkileşime girerek hekzaflorosilikat oluşturduğunu bildirmiştir. ${ }^{20}$ HF asidin yüzeyde meydana getirdiği mikroporoziteler sayesinde yüzey alanı artmakta ve bağlanma değerlerleri yükselmektedir. ${ }^{35} \mathrm{Bu}$ çalışmada da, HF asit uygulanmış Enamic ve Cerec yüzeylerinde yüzey morfolojisinin değiştiği, düzensiz ve dağınık mikroboşluklar meydana geldiği gözlenmiştir (Resim 7,8). HF asidin Enamic'in camsı yapısını kısmen çözdüğü ve bu şekilde polimer yapının ortaya çıkması sonucu pürüzlü bir yüzey oluştuğu görülmektedir.

Kombine pürüzlendirme uygulaması, bütün materyallerin kontrol grubu uygulamalarına göre istatistiksel olarak anlamlı şekilde daha yüksek yüzey pürüzlülüğüne neden olmuştır ( $p>0,05)$. Kombine pürüzlendirme işlemi sonrasında istatistiksel olarak en pürüzlü yüzeyi Cerasmart göstermiştir. Bunun sebebinin Cerasmart içerisinde bulunan mekanik pürüzlendirmeye çok yatkın olan baryum kristalleri olduğu düşünülmektedir. ${ }^{6}$ Kombine pürüzlendirme işlemi sonrasında Lava ve Enamic yüzeyleri arasında istatistiksel bir fark gözlenmemiştir ( $p>0,05)$. Enamic yüzeyin- de HF asit sonrası camsı matriksin çözündüğü ve polimer yapının ortaya çıktığı, kumlama ile polimer yapının da kısmen uzaklaşması sonrasında yüzey pürüzlülüğünün daha çok arttığı düşünülmektedir (Resim 9,10,11,12).

Bu çalışmanın sonuçlarına göre bütün materyallerde uygulanan yüzey hazırlık yöntemleri yüzey morfolojisini etkilemiştir. Kombine uygulama, sadece kumlama ve sadece HF asit uygulaması ile karşılaştıııldığında daha fazla yüzey pürüzlülüğüne neden olmuştur. Bununla birlikte bu çalışmanın bağlanma dayanımı testleri ile desteklenmesi gerekmektedir. Ayrıca farklı pürüzlendirme yöntemleri ve kombinasyonları da eklenerek CAD/CAM materyalleri için en uygun yüzey hazırlık yöntemlerinin tespit edilmesi ve bu verilerin klinik çalışmalarla da desteklenmesi gerekmektedir.

\section{SONUÇLAR}

Bu çalışmanın sınırları doğrultusunda, Cerec materyalinin en az pürüzlülük değerine sahip CAD/CAM blok olduğu gözlenmiştir. Kumlama işlemi, rezin, polimer infiltre ve feldspatik bazlı CAD/CAM materyallerinin yüzeyinde düzensiz bir morfoloji meydana getirmiş ve bu etki materyalin yapısına göre değişiklik göstermiştir. Diğer taraftan, kumlama sonrası hidroflorik asit uygulaması polimer infiltre ve feldspatik CAD/CAM bloklarının iç yapısında daha fazla retantif yüzey oluşumuna neden olmuştur.

\section{KAYNAKLAR}

1. Chavali R, Nejat AH, Lawson NC. Machinability of CADCAM materials. J Prosthet Dent 2017; 118: 194-199.

2. Awada A, Nathanson D. Mechanical properties of resin-ceramic CAD/CAM restorative

materials. J Prosthet Dent 2015; 114: 587-593.

3. Stawarczyk B, Awad D, llie N. Blue-Light Transmittance of Esthetic Monolithic CAD/CAM Materials With Respect to Their Composition, Thickness, and Curing Conditions. Oper Dent 2016; 41: 531-540.

4. Goujat $A$, Abouelleil $H$, Colon $P$, Jeannin $C$, Pradelle $N$. et all. Marginal and internal fit of CAD-CAM inlay/onlay restorations: A systematic review of in vitro studies. J Prosthet Dent 2019; 121: 590-597.

5. Yoshihara K, Nagaoka N, Maruo Y, Nishigawa G, Irie M. et al. Sandblasting may damage the surface of composite CAD-CAM blocks. Dent Mater 2017; 33: e124-e135.

6. Lise DP, Van Ende A, De Munck J, Yoshihara K, Nagaoka N. et all. Light irradiance through novel CAD-CAM block materials and degree of conversion of composite cements. Dent Mater 2018; 34: 296-305.

7. Park JH, Choi YS. Microtensile bond strength and micromorphologic analysis of surface-treated resin nanoceramics. J Adv Prosthodont 2016; 8: 275-284.

8. Capa N, Say EC, Celebi C, Casur A. Microtensile bond strengths of adhesively bonded polymer-based CAD/ CAM materials to dentin. Dent Mater J 2019; 8;38: 75-85.

9. Krämer N, Lohbauer U, Frankenberger R. Adhesive 
luting of indirect restorations. Am J Dent 2000; 13(Spec No): 60D-76D.

10. Peumans M, Hikita K, De Munck J, Van Landuyt K, Poitevin $A$, et all. Effects of ceramic surface treatments on the bond strength of an adhesive luting agent to CAD-CAM ceramic. J Dent 2007; 35: 282-288.

11. Vargas MA, Bergeron $C$, Diaz-Arnold A. Cementing all-ceramic restorations: recommendations for success. J Am Dent Assoc 2011;142: 20S-24S.

12. Papia $E$, Larsson $C$. Bonding between oxide ceramics and adhesive cement systems: a systematic review. J Biomed Mater Res B Appl Biomater 2014;102: 395-413.

13. Spitznagel $F A$, Vuck $A$, Gierthmühlen $P C$, Blatz $M B$, Horvath SD. Adhesive Bonding to Hybrid Materials: An Overview of Materials and Recommendations. Compend Contin Educ Dent 2016; 37: 630-637.

14. Ali A, Takagaki T, Naruse Y, Abdou A, Nikaido T. et all. The effect of elapsed time following alumina blasting on adhesion of CAD/CAM resin block to dentin. Dent Mater $\mathrm{J}$ 2019; 38: 354-360.

15. Moravej-Salehi E, Moravej-Salehi E, Valian A. Surface topography and bond strengths of feldspathic porcelain prepared using various sandblasting pressures. J Investig Clin Dent 2016; 7: 347-354.

16. Tzanakakis EG, Tzoutzas IG, Koidis PT. Is there a potential for durable adhesion to zirconia restorations? A systematic review. J Prosthet Dent 2016; 115: 9-19.

17. Özcan M, Volpato CÂ. Surface Conditioning and Bonding Protocol for Nanocomposite Indirect Restorations: How and Why? J Adhes Dent 2016; 18: 82.

18. Chaar MS, Passia N, Kern M. Ten-year clinical outcome of three-unit posterior FDPs made from a glass-infiltrated zirconia reinforced alumina ceramic (In-Ceram Zirconia). J Dent 2015; 43: 512-517.

19. Tian T, Tsoi JK, Matinlinna JP, Burrow MF. Aspects of bonding between resin luting cements and glass ceramic materials. Dent Mater 2014; 30: 147-162.

20. Della Bona A, Nogueira AD, Pecho OE. Optical properties of CAD-CAM ceramic systems. J Dent 2014; 42: $1202-1209$.

21. Campos F, Almeida CS, Rippe MP, de Melo RM, Valandro LF, et all. Resin Bonding to a Hybrid Ceramic: Effects of Surface Treatments and Aging. Oper Dent 2016; 41: 171-178.

22. Pieger S, Salman A, Bidra AS. Clinical outcomes of lithium disilicate single crowns and partial fixed dental prostheses: a systematic review. J Prosthet Dent 2014; 112: 22-30.

23. Özcan M, Volpato CÂ. Surface Conditioning and Bonding Protocol for Polymer-infiltrated Ceramic: How and Why?. Adhes Dent 2016; 18: 174-175.

24. Yañez MJ, Barbosa SE. Changes in particle area measurements due to SEM accelerating voltage and magnifi- cation. Microsc Res Tech. 2003; 61: 463-468.

25. Posritong $S$, Borges AL, Chu TM, Eckert GJ, Bottino MA et all. The impact of hydrofluoric acid etching followed by unfilled resin on the biaxial strength of a glass-ceramic. Dent Mater 2013; 29: e281-290.

26. Elsaka SE. Bond strength of novel CAD/CAM restorative materials to self-adhesive resin cement: the effect of surface treatments. J Adhes Dent 2014; 16: 531-540.

27. Fonseca RG, Martins SB, de Oliveira Abi-Rached F, Dos Santos Cruz CA. Effect of different airborne-particle abrasion/bonding agent combinations on the bond strength of a resin cement to a base metal alloy. J Prosthet Dent 2012; 108: 316-323.

28. Tschernitschek H, Borchers L, Geurtsen W. Nonalloyed titanium as a bioinert metal--a review. Quintessence Int 2005; 36: 523-530.

29. Strasser $T$, Preis $V$, Behr $M$, Rosentritt M. Roughness, surface energy, and superficial damages of CAD/CAM materials after surface treatment. Clin Oral Investig 2018; 22: 2787-2797.

30. Flury S, Schmidt SZ, Peutzfeldt A, Lussi A. Dentin bond strength of two resin-ceramic computer-aided design/ computer-aided manufacturing (CAD/CAM) materials and five cements after six months storage. Dent Mater J 2016; 35: 728-735.

31. Neis CA, Albuquerque NL, Albuquerque Ide S, Gomes EA, Souza-Filho CB. et all. Surface treatments for repair of feldspathic, leucite - and lithium disilicate-reinforced glass ceramics using composite resin. Braz Dent J 2015; 26: 152-155.

32. Frankenberger $R$, Hartmann VE, Krech $M$, Krämer N, Reich S. et al. Adhesive luting of new CAD/CAM materials. Int J Comput Dent. 2015; 18: 9-20.

33. Blatz MB, Sadan A, Blatz $U$. The effect of silica coating on the resin bond to the intaglio surface of Procera AllCeram restorations. Quintessence Int 2003; 34: 542-547.

34. Amaral R, Ozcan M, Bottino MA, Valandro LF. Microtensile bond strength of a resin cement to glass infiltrated zirconia-reinforced ceramic: the effect of surface conditioning. Dent Mater 2006; 22: 283-290.

35. Peumans $M$, Van Meerbeek $B$, Yoshida Y, Lambrechts P, Vanherle G. Porcelain veneers bonded to tooth structure: an ultra-morphological FE-SEM examination of the adhesive interface. Dent Mater 1999; 15: 105-119.

36. Yen TW, Blackman RB, Baez RJ. Effect of acid etching on the flexural strength of a feldspathic porcelain and a castable glass ceramic. J Prosthet Dent 1993; 70: 224233. 